\title{
The aeromycological studies on the occurrence of pathogenic fungal spores for plants in subalpine Karkonosze National Park
}

\author{
Aeromikologiczne badania występowania zarodników \\ grzybów patogenicznych dla roślin w piętrze subalpejskim \\ Karkonoskiego Parku Narodowego
}

\author{
Wojciech Pusz, Włodzimierz Kita
}

\begin{abstract}
Summary
Fungi occurring as saprophytes or parasites on a variety of substrata. Concentrations of airborne fungi depend on several factors f.ex.: weather conditions, vegetation, height above the sea level and human activities. The experiment was conducted in $2011-2012$. The occurence of plant pathogenic fungi was found in the air of subalpine zone of Karkonosze National Park and in Izerskie Mountains. Air samples were taken from 3 locations on the Karkonosze Mts and one from Izerskie Mts. To examine the air Air Ideal 3P sampler and acidified PDA (Potato Dextrose Agar) medium were used. The highest numbers of CFU $/ \mathrm{m}^{3}$ air (Colony Forming Unit of $1 \mathrm{~m}^{3}$ air) of fungus were isolated from the Hala Izerska in Izerskie Mts on April 2011, and Szrenica top in Karkonosze Mts on September 2011. Cladosporium cladosporioides was the most abundant species at all locations (up to 30\%) followed by Alternaria alternata (16-20\%), Fusarium spp. (up to $10 \%$ ) and Sclerotinia sclerotiorium (up to 6\%). The genus Cladosporium is one of the most abundant airborne fungi. Also A. alternata shows a similar pattern in response, like another fungi species Fusarium or S. sclerotiorium.
\end{abstract}

Key words: fungi, bioaerosol, high mountains aeromycology

\section{Streszczenie}

W latach 2011-2012 przeprowadzono badania aeromikologiczne w odstępach 3-4 tygodniowych od maja do października. Badania wykonano metodą zderzeniową przy użyciu urządzenia Air Ideal 3P. Pomiar był wykonywany w trzech lokalizacjach, w piętrze subalpejskim Karkonoskiego Parku Narodowego oraz porównawczo na Hali Izerskiej w Górach Izerskich. W trakcie przeprowadzonych badań stwierdzono występowanie zarodników 34 gatunków grzybów w pierwszym roku i 25 gatunków w drugim roku prowadzenia badań. Występowały zarodniki grzybów zarówno saprotroficznych, jak i patogenicznych dla roślin. Wśród tych drugich największym udziałem charakteryzował się gatunek Cladosporium cladosporioides - 25,4\% wszystkich uzyskanych zarodników w roku 2011 i $28,8 \%$ w drugim roku badań. Drugim gatunkiem patogenicznym dla roślin, którego zarodniki występują w dużym nasileniu w piętrze subalpejskim Karkonoszy był grzyb Alternaria alternata. W pierwszym roku badań stanowił on $24 \%$ wszystkich stwierdzonych zarodników, a w 2012 roku - 16,4\%. W obydwu latach badań obserwowano także występowanie w powietrzu zarodników Sclerotinia sclerotiorum na wszystkich obiektach badawczych. Oprócz wspomnianych gatunków w powietrzu piętra subalpejskiego Karkonoszy oraz na Hali Izerskiej notowano także zarodniki innych patogenów, jak np. Botrytis cinerea czy też Ulocladium botrytis. W powietrzu, w piętrze subalpejskim Karkonoszy oraz na Hali Izerskiej stwierdzono także obecność zarodników grzybów rodzaju Fusarium.

Słowa kluczowe: grzyby w bioaerozolu, aeromikologia, piętro subalpejskie

\footnotetext{
Uniwersytet Przyrodniczy we Wrocławiu

Katedra Ochrony Roślin

Pl. Grunwaldzki 24A, 50-363 Wrocław

wojciech.pusz@up.wroc.pl
} 


\section{Wstęp / Introduction}

W powietrzu obecne są wszystkie organy grzybów, w tym zarodniki, które są zdolne do przemieszczania się wraz z wiatrem na dalsze odległości (Dowd i Maier 1999). Grzyby w powietrzu moga powodować alergie, a także poważniejsze zaburzenia zdrowia, jak np. astmę (Asan i wsp. 2002; Kurup i wsp. 2002; Ogórek i wsp. 2012a, b). oraz stanowić zagrożenie dla roślin jako źródło infekcji (Meredith 1973; Dowd i Maier 1999; Ogórek i wsp. 2012b). Uwzględniając ten aspekt, niektórzy autorzy upatrują $\mathrm{w}$ badaniach aeromikologicznych jeden $\mathrm{z}$ elementów sygnalizacji pojawu chorób roślin (Dowd i Maier 1999). Może to być szczególnie ważne w przypadku grzybów, które są zdolne do przemieszczania się z wiatrem na większe odległości (Palti i Cohen 1980) pokonując także naturalne bariery, jak np. góry (Vaish i wsp. 2011). Klarič i Pepeljnjak (2006) stwierdzili w powietrzu górskim, na wysokości 800-900 m n.p.m. w rejonie Zagrzebia, obecność zarodników grzybów rodzajów: Cladosporium, Alternaria, a także Fusarium, Sclerotinia czy też Botrytis. Potwierdzają to także badania innych autorów (Ogórek i wsp. 2012a, b)

Celem przeprowadzonych badań było określenie składu gatunków grzybów, których zarodniki występuja w powietrzu, w piętrze subalpejskim Karkonoszy ze szczególnym uwzględnieniem grzybów patogenicznych dla roślin.

\section{Materiały i metody / Materials and methods}

Badania aeromikologiczne były prowadzone w latach 2011-2012, w odstępach 3-4 tygodniowych od maja do października. Badania wykonano metoda zderzeniową przy użyciu urządzenia Air Ideal 3P. Urządzenie zasysając powietrze atmosferyczne pobierało również obecne w powietrzu zarodniki grzybów, które trafiały na szalkę Petriego z zakwaszoną kwasem cytrynowym pożywką PDA (Potato Dextrose Agar, Biocorp). Urządzenie zaprogramowano na pobieranie prób o objętości 50 litrów. Pomiar był wykonywany w trzech lokalizacjach, w piętrze subalpejskim Karkonoskiego Parku Narodowego (Równia pod Śnieżką, Spalona Strażnica, Szrenica) oraz porównawczo na Hali Izerskiej w Górach Izerskich. Każdy pomiar wykonany był w trzech powtórzeniach po 9 szalek każdy. Urządzenie podczas pobierania próbek zlokalizowane było na wysokości $1,5 \mathrm{~m}$ od podłoża. Następnie szalki przechowywane były w warunkach temperatury pokojowej $\left(20-22^{\circ} \mathrm{C}\right)$ przez okres $7-10 \mathrm{dni}$. Kolejnym etapem doświadczenia było oznaczenie wyrosłych grzybów do gatunku oraz określenie liczby kolonii. Liczbę kolonii grzybów wyrosłych na szalce przeliczano na $1 \mathrm{~m}^{3}$ powietrza według wzoru:

$$
\mathrm{X}=(\mathrm{a} \times 1000) / \mathrm{V}
$$

$\mathrm{X}$ - liczba jednostek tworzących kolonie (JTK) w $1 \mathrm{~m}^{3}$ powietrza, a - suma kolonii grzybów, które wyrosły na szalce pobranej próbki powietrza atmosferycznego, V objętość pobranego powietrza atmosferycznego w litrach.

\section{Wyniki i dyskusja / Results and discussion}

Stwierdzono występowanie zarodników 34 gatunków grzybów w pierwszym roku (tab. 1) i 25 gatunków w drugim roku prowadzenia badań (tab. 2). Stwierdzono występowanie zarodników grzybów zarówno saprotroficznych, jak i patogenicznych dla roślin. Wśród tych drugich największym udziałem charakteryzował się Cladosporium cladosporioides - 25,4\% wszystkich uzyskanych zarodników w roku 2011 i 28,8\% w drugim roku badań. Największe stężenie zarodników C. cladosporioides stwierdzano w czerwcu, w pierwszym roku badań na wszystkich stanowiskach badawczych (rys. 1). W drugim roku doświadczenia najwyższe stężenie zarodników tego gatunku stwierdzono w czerwcu na Równi pod Śnieżką, na Spalonej Strażnicy oraz na Hali Izerskiej, gdzie zanotowano blisko $1960 \mathrm{JTK} / \mathrm{m}^{3}$. Na Szrenicy najwyższe stężenie C. cladosporioides odnotowano we wrześniu. Drugim gatunkiem patogenicznym dla roślin, którego zarodniki występują w dużym nasileniu w piętrze subalpejskim Karkonoszy był grzyb Alternaria alternata. Grzyb ten stanowi z reguły największy udział spośród gatunków występujących w powietrzu na stanowiskach zlokalizowanych zarówno w miastach, jak i poza nimi (Tomassetti i wsp. 2011; Almaguer-Chávez i wsp. 2012). W pierwszym roku badań stanowił on $24 \%$ wszystkich stwierdzonych zarodników, a w 2012 roku $16,4 \%$. Najwyższe stężenie zarodników tego gatunku odnotowano w czerwcu 2011 roku na Hali Izerskiej, gdzie stężenie zarodników $\mathrm{w} \mathrm{m} \mathrm{m}^{3}$ powietrza wynosiło 2700 . Zbliżone wyniki uzyskała Maya-Manzano i wsp. (2012). Stwierdziła, że największe stężenie zarodników A. alternata przypada na maj oraz październik. Znacznie niższe stężenia inokulów A. alternata stwierdzono w piętrze subalpejskim Karkonoszy. W czerwcu najwyższe wartości $\mathrm{JTK} / \mathrm{m}^{3}$ notowano na Równi pod Śnieżką (560), Spalonej Strażnicy (780) oraz na Szrenicy (640). Jednak na tym stanowisku, podobnie jak to miało miejsce w przypadku C. cladosporioides, najwyższe stężenie zarodników stwierdzono we wrześniu i wynosiło ono $780 \mathrm{JTK} / \mathrm{m}^{3}$. $\mathrm{W}$ drugim roku badań sytuacja była podobna. W czerwcu stwierdzono najwyższe stężenia zarodników A. alternata zarówno w Karkonoszach (Równia pod Śnieżką: $760 \mathrm{JTK} / \mathrm{m}^{3}$; Spalona Strażnica: $160 \mathrm{JTK} / \mathrm{m}^{3}$; Szrenica: $560 \mathrm{JTK} / \mathrm{m}^{3}$ ), jak i na Hali Izerskiej - $340 \mathrm{JTK} / \mathrm{m}^{3}$. W obydwu latach badań obserwowano także występowanie w powietrzu zarodników Sclerotinia sclerotiorum na wszystkich obiektach badawczych. Udział tego patogena kształtował się na poziomie $6,9 \% \mathrm{w}$ pierwszym roku badań oraz $5,5 \%$ w drugim roku prowadzenia obserwacji. Najwyższe stężenie jednostek tworzących kolonie tego gatunku odnotowano w 2011 roku w lipcu na wszystkich stanowiskach badawczych (od $40 \mathrm{JTK} / \mathrm{m}^{3}$ na Równi pod Śnieżką do $320 \mathrm{JTK} / \mathrm{m}^{3}$ na Spalonej Strażnicy), natomiast W roku 2012 sytuacja nie była jednorodna. Oprócz wspomnianych gatunków w powietrzu piętra subalpejskiego Karkonoszy oraz na Hali Izerskiej notowano także zarodniki innych patogenów, jak np. Botrytis cinerea (1,2\% ogółu zarodników w roku 2011 i 2,8\% w 2012 roku), Cladosporium herbarum $(2,9 \% \mathrm{w}$ pierwszym roku 
Tabela 1. Występowanie zarodników grzybów i organizmów grzybopodobnych w powietrzu piętra subalpejskiego Karkonoszy i w Górach Izerskich in $2011\left(\mathrm{JTK} / \mathrm{m}^{3}\right)$

Table 1. The occurence of fungi and fungi like organisms spores in air of subalpine zone of Karkonosze and in Izerskie Mountais in $2011\left(\mathrm{CFU} / \mathrm{m}^{3}\right)$

\begin{tabular}{|c|c|c|c|c|c|c|c|c|c|c|c|c|c|c|c|c|c|c|c|c|c|c|c|c|}
\hline \multirow{2}{*}{ Gatunek - Species } & \multicolumn{6}{|c|}{ Równia pod Śnieżką } & \multicolumn{6}{|c|}{ Spalona Strażnica } & \multicolumn{6}{|c|}{ Szrenica } & \multicolumn{5}{|c|}{ Hala Izerska } & \multirow{2}{*}{$\%$} \\
\hline & $\mathrm{V}$ & VI & VII & VIII & IX & $\mathrm{X}$ & V & VI & VII & VIII & IX & $\mathrm{X}$ & $\mathrm{V}$ & VI & VII V & VIII $\mid$ & IX & $\mathrm{X}$ & VI & VII & VIII & IX & $X$ & \\
\hline Alternaria alternata & 120 & 240 & & 1402 & 220 & & & 260 & 260 & 140 & 460 & 80 & 180 & 320 & 1202 & \begin{tabular}{l|l}
220 & 4
\end{tabular} & 480 & 240 & 2700 & 560 & 240 & 420 & 180 & 24,0 \\
\hline Botrytis cinerea & & & & 80 & & & & & & 100 & 100 & & & & & & 100 & & & & & & & 1,2 \\
\hline $\begin{array}{l}\text { Cladosporium } \\
\text { cladosporioides }\end{array}$ & & 560 & 180 & 801 & 140 & & 120 & 780 & 400 & 160 & 500 & & 40 & 640 & 2601 & 1407 & 780 & 300 & 1960 & 220 & 260 & 240 & 240 & 25,4 \\
\hline C. herbarum & 140 & 40 & & & & 180 & & & & & 160 & 260 & 120 & & & & & & & & & & & 2,9 \\
\hline Drechslera sorokiniana & & & & & & & & & & & & & & & & 40 & & & 40 & & & & & 0,3 \\
\hline D. teres & & & & & & & & & & & & & & & & & & & & 60 & 40 & & & 0,3 \\
\hline Epicoccum purpurascens & & & & & & 60 & & & & 160 & 240 & 40 & & & & 1402 & 280 & 80 & & & 220 & 40 & 40 & 4,1 \\
\hline Fusarium culmorum & & & & & & & & & & & & & & 20 & & & & & & & 40 & & & 0,2 \\
\hline F. equiseti & 60 & & & 60 & & & & & & 60 & & & 80 & & & & & & & & & & & 0,8 \\
\hline F. oxysporum & 40 & & & & & & & & & & & & & & & & & & & & & & & 0,1 \\
\hline F. sporotrichoides & & & & & 100 & & & & & & & & & & & & & & & & & & & 0,3 \\
\hline Giberella avenacea & & & & & & 40 & & & & & & & & & & & & 40 & & & 60 & & & 0,4 \\
\hline Gliocladium catenulatum & & & & & & 180 & & & & & & 140 & & & & & & & & & & & & 1,0 \\
\hline Penicillium notatum & 120 & & 40 & & & & 100 & & 40 & 120 & & 40 & 40 & & 80 & & 140 & 80 & 80 & 140 & & 120 & 40 & 3,7 \\
\hline Penicillium spp. & & & & & & & & & & & & & & & & & & & 240 & & & & & 0,8 \\
\hline P. velutinum & & & & & & & & & & & & & & & & & 100 & & & & & & & 0,3 \\
\hline P. waksmani & & & & & & & & & & & 140 & 80 & & 40 & & & 120 & & & & & & 60 & 1,4 \\
\hline Phoma eupyrena & & 80 & & & 40 & & & & & & & & & 60 & & & & & & & & & 40 & 0,7 \\
\hline$P$. fimeti & & & & & & & & & & & & & & & & & & 60 & & & & & & 0,2 \\
\hline Phoma spp. & & & & & & & & & & & & & 40 & & & & & & & 240 & & & & 0,9 \\
\hline Phytophthora spp. & 40 & & & & & & & & & & & & & & & & & & & & & & & 0,1 \\
\hline Rhizoctonia solani & & & 220 & & & & & & & & & & & & & & & & & & 40 & & & 0,8 \\
\hline Sclerotinia sclerotiorium & 80 & 100 & 40 & 140 & & 40 & 60 & 80 & 320 & 60 & 120 & & 60 & 160 & 2801 & 1001 & 160 & & 120 & 160 & 80 & & & 6,9 \\
\hline Ulocladium botrytis & & & & 140 & & & & & 40 & & & 80 & & & & 40 & & 80 & 360 & 140 & 140 & & & 3,2 \\
\hline Verticillium albo-atrum & & & & & & & & & & & & & & 80 & & & & & & & & & & 0,3 \\
\hline $\begin{array}{l}\text { Pozostałe gatunki } \\
\text { Other species }\end{array}$ & & & & & & & & & & & & & & & & & & & & & & & & 19,7 \\
\hline Suma - Sum & 600 & 1200 & 1140 & 760 & 980 & 700 & 380 & 1424 & 1120 & 900 & 3145 & 760 & 6601 & 1720 & 7808 & 8002 & 2660 & 1140 & 5900 & 1980 & 1120 & 940 & 7201 & $\overline{100,0}$ \\
\hline
\end{tabular}

Tabela 2. Występowanie zarodników grzybów w powietrzu piętra subalpejskiego Karkonoszy i w Górach Izerskich in $2012\left(\mathrm{JTK} / \mathrm{m}^{3}\right)$ Table 2. The occurence of fungi spores in air of subalpine zone of Karkonosze and in Izerskie Mountais in $2012\left(\mathrm{CFU} / \mathrm{m}^{3}\right)$

\begin{tabular}{|c|c|c|c|c|c|c|c|c|c|c|c|c|c|c|c|c|c|c|c|c|c|c|c|c|}
\hline \multirow{2}{*}{ Gatunek - Species } & \multicolumn{6}{|c|}{ Równia pod Śnieżką } & \multicolumn{6}{|c|}{ Spalona Strażnica } & \multicolumn{6}{|c|}{ Szrenica } & \multicolumn{5}{|c|}{ Hala Izerska } & \multirow{2}{*}{$\%$} \\
\hline & $\mathrm{V}$ & VI & VII & VIII & IX & $X$ & $\mathrm{~V}$ & $\mathrm{VI}$ & & VIII & IX & $\mathrm{X}$ & V & VI & VII & VIII & IX & $\mathrm{X}$ & VI & VII & VIII & IX & $\mathrm{X}$ & \\
\hline 1 & 2 & 3 & 4 & 5 & 6 & 7 & 8 & 9 & 10 & 11 & 12 & 13 & 14 & 15 & 16 & 17 & 18 & 19 & 20 & 21 & 22 & 23 & 24 & 25 \\
\hline Alternaria alternata & & 760 & & 360 & 80 & 20 & 20 & 160 & & 140 & 140 & 120 & 60 & 560 & 480 & 60 & & 20 & 340 & 180 & 60 & 320 & 200 & 16,4 \\
\hline Botrytis cinerea & & & & & & & & 140 & & & 20 & 20 & & & & & & & 140 & 120 & 120 & 80 & 50 & 2,8 \\
\hline $\begin{array}{l}\text { Cladosporium } \\
\text { cladosporioides }\end{array}$ & & 980 & 360 & 80 & 40 & 40 & & 320 & 40 & 40 & & 60 & 160 & 240 & 380 & 140 & 1460 & 300 & 180 & 240 & 120 & 1560 & 400 & 28,8 \\
\hline C. herbarum & & & & & & & & & 60 & & 500 & 300 & & 300 & & & & & 60 & & & & & 4,9 \\
\hline Drechslera sorokiniana & & & & & & & & & & & 80 & 50 & & & 160 & & & & & & & 240 & 100 & 2,5 \\
\hline Fusarium culmorum & & & & & & & & & & & & & & & & & & & & & & 60 & 20 & 0,3 \\
\hline F. equiseti & & & & & & & & & & & 480 & 340 & & & & & & & & & & & & 3,3 \\
\hline Gliocladium catenulatum & & & & & & & & & & & & & & & 80 & & & & & 180 & & & & 1,0 \\
\hline Penicillium citrinum & 349 & & & & & & & & & & & & & & & & & & & & & 40 & 20 & 1,6 \\
\hline
\end{tabular}




\begin{tabular}{|c|c|c|c|c|c|c|c|c|c|c|c|c|c|c|c|c|c|c|c|c|c|c|c|c|}
\hline 1 & 2 & 3 & 4 & 5 & 6 & 7 & 8 & 9 & 10 & 11 & 12 & 13 & 14 & 15 & 16 & 17 & 18 & 19 & 20 & 21 & 22 & 23 & 24 & 25 \\
\hline Penicillium notatum & 40 & & & & 60 & 60 & & & 80 & & & 20 & & & 60 & & 1601 & 100 & 60 & & 40 & & & 2,7 \\
\hline Penicillium spp. & & & & & & & & & & & & & & & & & & & & & & 140 & 10 & 0,6 \\
\hline P. velutinum & & & & & & & & & & 40 & & 50 & & & & & & & & & & & & 0,4 \\
\hline P. vermiculatum & 140 & & & & & & & & & & & & & & & & & & & & & & & 0,6 \\
\hline P. waksmani & & & & & & & 140 & & 60 & & & & 40 & & & 80 & & 40 & 120 & 220 & & 120 & 40 & 3,5 \\
\hline Phoma eupyrena & & & & & & & & & & & & & & & & & & & & & & 160 & 40 & 0,8 \\
\hline Phoma spp. & & & 240 & & & & & & & & & & 40 & & & & & & & & & & & 1,1 \\
\hline Rhizoctonia solani & & 160 & & & & & & & & & & & & 220 & & & & & & & & & & 1,5 \\
\hline Sclerotinia sclerotiorium & & 360 & & & 60 & 120 & & & & & & & 120 & & 60 & 40 & 200 & & 180 & 160 & 60 & & & 5,5 \\
\hline Ulocladium botrytis & & & & & & & & & & & & & 20 & \begin{tabular}{l|l}
140 & 2 \\
\end{tabular} & 240 & & & & & 40 & 20 & 100 & 50 & 2,5 \\
\hline $\begin{array}{l}\text { Pozostałe gatunki } \\
\text { Other species }\end{array}$ & & & & & & & & & & & & & & & & & & & & & & & & 19.2 \\
\hline Suma - Sum & 549 & 274 & 760 & 620 & 280 & 4001 & 1807 & 700 & 2402 & 2801 & 1280 & 10607 & 7801 & 19402 & 21207 & 7602 & 23604 & 48 & 1080 & 114 & & 3060 & 103 & 100,0 \\
\hline
\end{tabular}

badań i 4,9\% w drugim roku prowadzenia badań) czy też Ulocladium botrytis (odpowiednio 3,2\% i 2,5\% wszystkich uzyskanych zarodników). W powietrzu, w piętrze subalpejskim Karkonoszy oraz na Hali Izerskiej stwierdzono także obecność zarodników grzybów rodzaju Fusarium. W pierwszym roku badań stanowiły one 1,8\% wszystkich uzyskanych zarodników, by w kolejnym roku osiągnąć $3,6 \%$ ogółu zarodników. Pozostałe gatunki patogeniczne dla roślin stanowiły niewielki procent wszystkich uzyskanych zarodników grzybów. Znajduje to potwierdzenie w pracach innych badaczy (Klarič i Pepeljnjak 2006; Ogórek i wsp. 2012a, b).

\section{Wnioski / Conclusions}

1. Dominującymi grzybami obecnymi w powietrzu piętra subalpejskiego Karkonoszy oraz na Hali Izerskiej były grzyby rodzaju: Cladosporium, Fusarium oraz A. alternata i S. sclerotorium.

2. Przy napływie mas powietrza $z$ kierunków południowych na badanym obszarze może występować rozprzestrzenianie się grzybów patogenicznych dla roślin pochodzących z obszaru Czech.

\section{Literatura / References}

Almaguer-Chávez M., Rojas-Flores T., Dobal-Amador V., Batista-Mainegra A., Rives-Rodríguez N., Jesus-Aira M., HernándezLauzardo A.N., Hernández-Rodríguez A. 2012. Aerobiological dynamics of potentially pathogenic fungi in a rice agroecosystem in La Habana, Cuba. Aerobiologia 28: 177-183.

Asan A., Ilhan S., Sen B., Erkara I.P., Filik C., Cabuk A., Demirei R., Ture M., Okten S.S., Tokur S. 2004. Airborne fungi and actinomycetes concentrations in the air of Eskisehir city (Turkey). Indoor and Built Environment 13 (1): 63-74.

Dowd S.C., Maier R.M. 1999. Aeromicrobiology. In: „Environmental Microbiology” (R.M. Maier, I.L. Pepper, C.P. Gerba, eds.). Academic Press, San Diego, USA, 330 pp.

Klarič M.S., Pepeljnjak S. 2006. A year-round aeromycological study in Zagreb area, Croatia. Ann. Agric. Environ. Med. 13 : 55-64.

Kurup V.P., Shen H.D., Vijay H. 2002. Immunobiology of fungal allergens. Int. Arch. Allergy Immunol. 129: 181-191.

Maya-Manzano J.M., Fernández-Rodríguez S., Hernández-Trejo F., Díaz-Pérez G., Gonzalo-Garijo A., Silva-Palacios I., MuñozRodríguez A.F., Tormo-Molina R. 2012. Seasonal mediterranean pattern for airborne spores of Alternaria. Aerobiologia 28: 515-525.

Meredith D.S. 1973. Significance of spore release and dispersal mechanism in plant disease epidemiology. Ann. Rev. Phytopathol. 11: 313-342.

Ogórek R., Lejman A., Pląskowska E., Bartnicki M. 2012a. Fungi in the mountain trails of the Snieznik Massif. Mikologia Lekarska 19 (2): 57-62.

Ogórek R., Lejman A., Pusz W., Miłuch A., Miodyńska P. 2012b. Charakterystyka i taksonomia grzybów z rodzaju Cladosporium. Mikologia Lekarska 19 (2): 80-85.

Palti J., Cohen Y. 1980. Downy mildew of cucurbits (Pseudoperonospora cubensis): the fungus and its hosts, distribution, epidemiology and control. Phytoparasitica (2): 109-147.

Tomassetti B., Lombardi A., Cerasani E., Di Sabatino A., Pace L., Ammazzalorso D., Verdecchia M. 2011. Mapping of Alternaria and Pleospora concentrations in Central Italy using meteorological forecast and neural network estimator. Aerobiologia, doi: 10.1007/s10453-012-9262-2 (online).

Vaish S.S., Ahmed S.B., Prakash K. 2011. First documentation on status of barley diseases from the high altitude cold arid TransHimalayan Ladakh region of India. Crop Prot. 30: 1129-1137. 